exercised their right to appeal, 14 (19\%) withdrew their application before tribunal, $20(27 \%)$ were regraded to informal status by the Responsible Medical Officer prior to tribunal and of those actually reaching the tribunal stage $34(47 \%)$ were detained and $5(7 \%)$ discharged. In total $34 \%$ were regraded to informal. Certainly there seems to be a trend of greater discharge rate than previously recognised. McCreadie (1989) commented on a trend in one psychiatric hospital in Scotland to allow 28 day detentions to run for the full length. Consequently it is tempting to say that this elevated discharge rate reflects a direct effect of appealing. Further evaluation is needed to clarify this point.

It is important that the right of patients to appeal against detention is looked on not only as a necessary and expensive evil but also as a way of promoting good clinical practice. Prompt and regular reviews of the legal status of patients, however provoked, may well enhance the quality of the clinical relationship between mental health professionals and their clients. A shift in the balance of power in the doctorpatient relationship toward a more equal basis can only be welcomed, while the benefits to those detained are obvious.

Winwick Hospital

Sara J. Cunningham

Winwick, Warrington WA28RR

\section{References}

Mawson, D. S. (1986) The function of Mental Health Review Tribunals under the Mental Health Act 1983. Medicine, Science \& Law, 26, 291-294.

MCCREADIE, R. G. (1989) The operation of the Mental Health (Scotland) Act 1984 in one psychiatric hospital. Health Bulletin, 47, 204-206.

\section{DeAR SiRS}

I note Dr Cunningham's comments and would like to make the following comments in reply.

(a) Only two of our patients withdrew from their tribunal prior to the tribunal date and these were not included in the data.

(b) None of our patients was discharged from Section 2 prior to their hearing at the Tribunal.

(c) Dr Cunningham has studied the legal outcome of appeals under both Section 2 and Section 3 and has found that of those reaching Tribunal, $34 \%$ were graded to informal. However, considering these patients are detained under both Section 2 and Section 3, this could merely reflect the improvement after treatment of those on Section 3. In my view, this needs further investigation as my figures have only considered patients on Section 2 and it is misleading to combine the two groups. (d) Dr Cunningham claims that $7 \%$ were discharged at the Tribunal but this is beyond the Tribunal's powers, the Tribunal having only the power to state whether the patient should be detained on a Section or should be regraded to informal. It is unclear how these patients were discharged.

Finally, the difference in discharge rate between Dr Cunningham's sample and our sample may simply reflect varying clinical practices which we found among the three hospitals which we studied, indicating the need for further evaluation of this method of appeals and detention as we have previously recommended.

\section{Meanwood Park Hospital}

J. M. O'DWYER

\title{
Guardianship and treatment
}

\section{DEAR SIRS}

We have recently been involved in some correspondence with the Mental Health Act Commission, which may be of interest to members.

We wrote for advice about procedure regarding the situation of patients who had been placed on a Guardianship order, who suffered from chronic mental illness, but whose main need was social care. Our anxiety arose about a particular case where such a patient might deteriorate from the point of view of their mental illness and need compulsory admission for treatment.

We wondered if fresh applications need to be made for Section 3 but received the following advice:

\begin{abstract}
"Thank you for your letter to the Commission received here on 21 June 1991, and the point you raise in it. I agree with your understanding of Section 19.2(d) of the Mental Health Act in that you can transfer from Guardianship to Section 3 under this Section of the Act without seeking a fresh treatment order. I must stress however, that this is my personal opinion only and cannot be regarded as formal legal advice as the Commission is unable to give this."
\end{abstract}

This obviously raises many questions about the use of Guardianship in vulnerable chronically mentally ill patients and may facilitate earlier treatment of such patients which would be desirable in certain selected cases.

We hope that this issue can be clarified further from the legal viewpoint but feel that this response may be of sufficient importance for wider debate.

Mark Ardern

St Charles Hospital

SEAN LYNCH 